\title{
Effects of climate variation on winter cereal production in Spain
}

\author{
C. Rodríguez-Puebla ${ }^{1, *}$, S. M. Ayuso ${ }^{1}$, M. D. Frías ${ }^{2}$, L. A. García-Casado ${ }^{3}$ \\ ${ }^{1}$ Department of Atmospheric Physics, University of Salamanca, 37008 Salamanca, Spain \\ ${ }^{2}$ Physics Institute of Cantabria, CSIC-University of Cantabria, 39005 Santander, Spain \\ ${ }^{3}$ Department of Mathematics, University of Salamanca, 37008 Salamanca, Spain
}

\begin{abstract}
Climate variables responsible for inter-annual variations in the winter cereal yield in Spain were identified and climate information was translated into crop production. Empirical orthogonal functions and correlation analyses were applied to regional and large-scale climate variables to ascertain the links between climate and winter cereal yield. Interactions between climate and winter cereal productivity in Spain can be summarized as follows: the start of the growing season depends on minimum temperature, and crop maturity is affected by drought, maximum temperature, sea-level air pressure, moisture fluxes, and the jet stream, as well as by indices of the Scandinavian Pattern, the North Atlantic Oscillation, and the Southern Oscillation. A statistical approach has been derived to describe variability in cereal productivity in Spain taking into account the previous potential predictors. In general, the best atmospheric conditions for increasing winter cereal productivity in Spain are warmer winters, cooler and wet springs, with prevalent meridional circulation at upper levels. The observed trend of increasing sea level pressure toward the western Mediterranean could cause a loss in the winter cereal yield.
\end{abstract}

KEY WORDS: Climate variability $\cdot$ Winter cereal $\cdot$ Principal component analysis $\cdot$ Regression model Resale or republication not permitted without written consent of the publisher

\section{INTRODUCTION}

Water shortage and an increase in extreme weather events (heat-waves, floods and droughts) may cause higher crop-yield variability. Agricultural losses are very dependent on weather, and farmers need climatic and seasonal forecast information that anticipates variations in crop production. Changes in climate could alter crop distribution, and policy-makers working in areas related to climate change should learn about the impact of climate change on crop yields.

The aim of this study is to investigate the sources of Spanish winter cereal productivity (CP) variations in the climate historical time series. Winter cereal is a major crop in Spain (about $14 \times 10^{3} \mathrm{t} \mathrm{yr}^{-1}$ ), accounting for approximately $10 \%$ of the annual European production (www.mapa.es/es/estadistica/pags/anuario/ introduccion.htm). Climate over the Iberian peninsula (IP) shows large inter-annual variations. Since 1978, temperatures have tended to increase, with maximums being more frequently significant than minimums (Moreno 2005), and precipitation has shown a decreasing trend, particularly in March (Corte-Real et al. 1998), with differences according to regions (Rodriguez-Puebla \& Brunet 2007). There is evidence of increasing frequency of climate extremes and variability (Frich et al. 2002, Alexander et al. 2006). Since the 1970 s, the crop time series have shown significant inter-annual variations and we assume that climate variations could cause CP fluctuations.

A number of studies have examined the effects of climate variability in relationship to crop yields (Sivakumar 2006). Some studies estimate the contribution of regional climate variables to yields (Nicholls 1997). Others consider the interactions between crops and teleconnection indices, such as the El Niño/Southern Oscillation (ENSO) or the North Atlantic Oscillation (NAO) (Phillips et al. 1998, Podesta et al. 1999, Jones \& Davis 2000, Alexandrov \& Hoogenboom 2001, Tao et al. 2004). Stenseth et al. (2002) reviewed the effects of 
ENSO and NAO on marine and terrestrial ecosystems. General Circulation Models (GCMs) provide new opportunities for investigating the impacts of climate change on agriculture. Within this line are the studies of Rosenzweig et al. (2002), who simulated the damage of heavy precipitation on crop growing, and Thomson et al. (2005), who found that winter wheat production under irrigation appears likely to increase under climate change. The simulation of winter wheat yields (Song et al. 2006) gives a trend towards yield increase in northern China and a yield decrease in southern China. Adejuwon (2006) obtained crop yield simulations from GCMs for Nigeria for 3 periods of the 21st century, explaining the lower yields in terms of global warming. In Europe, Schroter et al. (2005) analysed the vulnerability of crops due to climate change, and Harrison et al. (2000) assessed wheat yield simulation. Due to the imprecision of model simulations, Cantelaube \& Terres (2005) considered the multimodel seasonal forecast information to provide an ensemble of yield simulations, while Mearns et al. (2003) considered higher resolution models to study the impact of climate variability and change on agriculture. Hansen et al. (2006) and Hansen \& Sivakumar (2006) provided the advances in climate-based crop forecasting.

The estimation of the effects of climate variations on the production of Spanish winter cereal has only been evaluated at a few particular locations. For example, Vicente-Serrano et al. (2006) considered drought indices and remote sensing data to predict wheat and barley yields in Ebro valley and recently, Iglesias \& Quiroga (2007) evaluated the risk of climate variability on final crop yield at 5 sites in Spain. Therefore, we conducted this study to obtain the links between climate variables and the year-to-year winter Spanish $\mathrm{CP}$ variations. First, climatic signals were filtered by applying empirical orthogonal function (EOF) analysis to regional fields, such as precipitation, drought and temperatures, and to large-scale atmospheric fields such as sea-level pressure, moisture fluxes and jet stream. Correlation analysis between $\mathrm{CP}$ and climate fields allowed us to identify the variables that contribute to $\mathrm{CP}$ variations. An empirical/statistical model was derived to represent the response of $\mathrm{CP}$ to climate which considers the above-mentioned fields and the teleconnection indices. Different associations were found between the phases of cereal growth and the climate.

The results derived from our study help to obtain suitable standardized input variables for use with crop simulation models to be applied for crop management decisions and to learn about the agricultural impact of climate change. The data and methods used in this study are described in Section 2; Section 3 provides the results which include the characteristics of the regional and large-scale atmospheric fields that cause year-toyear CP variations, as well as some discussions about the procedure used to derive the statistical model; the most important conclusions are given in Section 4 .

\section{DATA AND METHODS}

Historical agricultural data, including crop yields (t) for land areas harvested $\left(\mathrm{hm}^{2}\right)$, were provided by government records from the Ministerio de Agricultura Pesca y Alimentación (MAPA). The major winter cereals in Spain are wheat, barley and rye, with available records covering the period 1972 to 2005. The yields at different locations distributed over Spain were aggregated to obtain the Spanish winter CP time series, which is defined as the yields relative to the harvested area. Fig. 1a shows the CP time series 1972 to 2005 and the observed increasing trend; Kendall's $z$-test gives the significant value of 3.5 (Press et al.
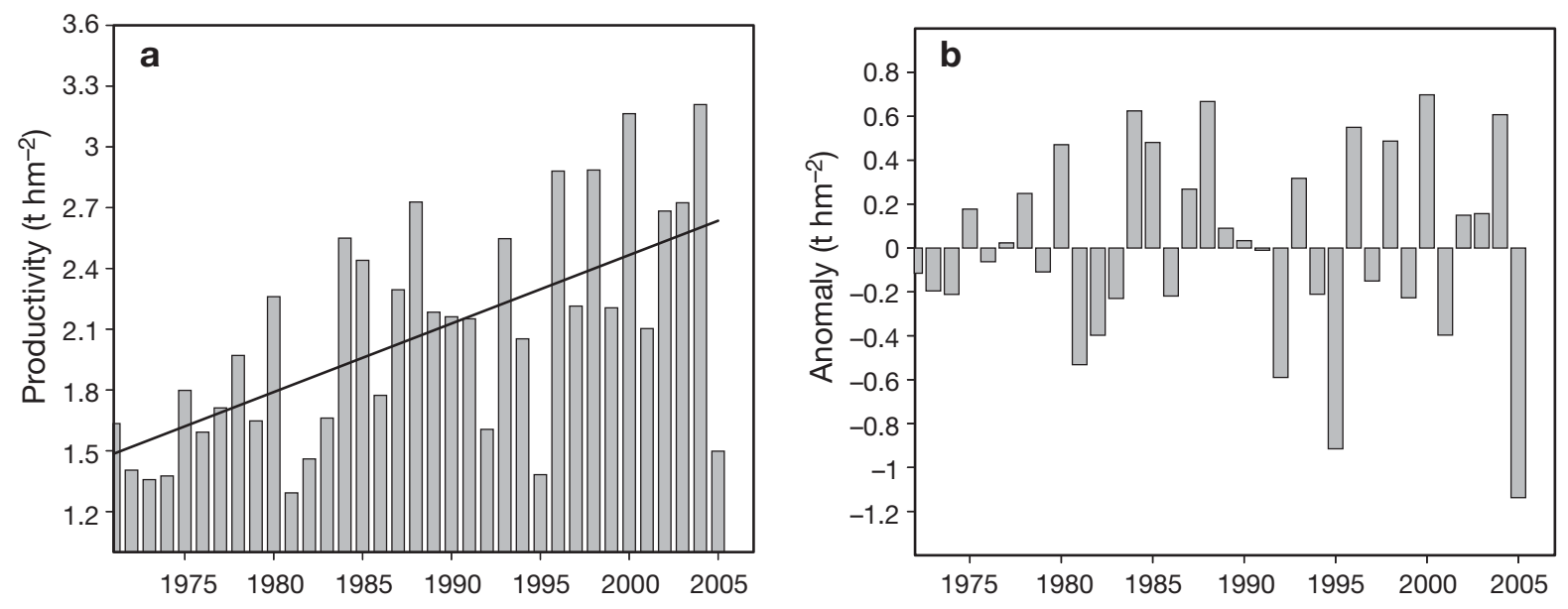

Fig. 1. Spanish winter cereal productivity (a) time series and (b) anomalies with respect to the trend in (a) 
1996). Among the causes of CP variability are changes in agricultural practices, technological improvement and the agricultural policies of the local governments; these effects cause a trend that is independent of climate (Lobell \& Field 2007). Therefore, a linear fit trend was subtracted from the data to obtain the anomalies. Fig. 1b shows the 1972 to 2005 time series of the anomalies with respect to the trend; anomalies are smaller earlier in the period than for the most recent years. Good productivity values correspond to the years 1984, 1988, 2000 and 2004, while low productivity values correspond to the years 1981, 1992, 1995 and 2005. Mean CP $\left( \pm\right.$ SD) is $2.1 \pm 0.4 \mathrm{t} \mathrm{ha}^{-1}$. The Jarque-Bera (JB) test measures the departure from normality (http://en.wikipedia.org/wiki/Jarque-Bera_test) and is based on the sample kurtosis $(-0.13)$ and skewness $(-0.45)$; the JB value for $\mathrm{CP}$ is 1.2 , which indicates good fit to the normal distribution.

Regional climate precipitation, and maximum and minimum temperatures were provided by the Meteorological Institutes of Spain and Portugal. The in situ data used corresponded to 55 stations irregularly distributed over the IP. Water capacity and drought are important variables for crop simulations. Therefore, we considered the Standardized Precipitation Index (SPI), which measures the departure of precipitation from the normal amount, as a measure of drought. The SPI was computed by fitting a gamma probability density function to the frequency distribution of precipitation of the monthly precipitation data (Hayes et al. 1999, Vicente-Serrano 2006).

The large-scale atmospheric fields used in this study are from the reanalysis data of NCEP/NCAR (Kalnay et al. 1996). The area considered is the part of the northern hemisphere within which the IP is situated and includes latitudes 25 to $80^{\circ} \mathrm{N}$ and longitudes $60^{\circ} \mathrm{W}$ to $30^{\circ} \mathrm{E}$. According to our results, the atmospheric fields that most affected CP were: sea level pressure (SLP), zonal and meridional moisture fluxes (QU and QV, respectively) and zonal wind at $200 \mathrm{hPa}$ level (JET). The contribution of the teleconnection indices to $\mathrm{CP}$ are also considered, the indices having been provided by the Climate Prediction Center (CPC) available online at www.cpc.ncep.noaa.gov/products/ MD_index.shtml (northern hemisphere teleconnection patterns and monthly atmospheric and sea-surface temperature indices), and from www.cru.uea.ac.uk/ $\mathrm{cru} /$ data/nao.htm for the case of the NAO.

Rotated and unrotated EOF analyses were performed to reduce the dimensions of the atmospheric fields while retaining signals of associated variance (von Storch \& Zwiers 1999, Jolliffe 2002). Area weighting was accomplished by multiplying the fields by the square root of the cosine of latitude. The comparison between correlation maps of $\mathrm{CP}$ with climatic fields and the spatial variation modes or EOFs allow us to select the potential predictors that capture the CP response to climate variability. Landau et al. (2000) developed a statistical model to represent the effects of weather on wheat yield in the UK; Alexandrov \& Hoogenboom (2000) applied regression models to describe the relationship between crop yield, precipitation and air temperature; Penalba et al. (2007) examined the influence of climate variability on the fluctuation of soybean yield in Argentina by using the multivariate regression method. We applied linear regression models to obtain the cereal yield response to climate variables as follows. First, the forward stepwise method selected the variables with forward entry into the model and backward removal. Second, we compared the stepwise regression solution with other subsets of regressions with the same number of predictors in order to confirm whether or not the stepwise solution was the best. Third, the performance of the model was evaluated by using cross-validation or by dividing the data into subsets and by repeating the fitting method to derive confidence intervals for the estimations. With these procedures we tried to avoid over-fitting and to ensure adequate degrees of freedom for the residuals. The ability of the model to derive the observed CP variations was measured by the correlation coefficient between observed and simulated CP data, taking into account the significance probability test $(p)$ and the standard interval errors (SE) of the correlation coefficients, which were obtained by a resampling procedure using the bootstrap method (Wilks 2006).

\section{RESULTS}

\subsection{Links between climate variables and CP}

Composite maps corresponding to the 4 years with the highest $\mathrm{CP}$ minus the 4 years with the lowest $\mathrm{CP}$ provide some information about the influence of climate variables on CP. For example, Fig. 2 shows the anomalies of precipitation, maximum temperature, SLP and geopotential at $500 \mathrm{hPa}$ level in May for the years with high $(1984,1988,2000$ and 2004) and low (1981, 1992, 1995 and 2005) productivity. Fig. 2a,b suggests that yield increases under abundant precipitation and lower maximum temperature. Low sea level pressure toward the southwestern Mediterranean and low geopotential at $500 \mathrm{hPa}$ or cooler air mass over the IP provide the best atmospheric conditions for increasing CP (Fig. 2c,d). Fig. 2e,f compares the JET for years with high and low CP. There is predominance of meridional atmospheric circulation at upper levels (200 hPa) for years with high CP. 

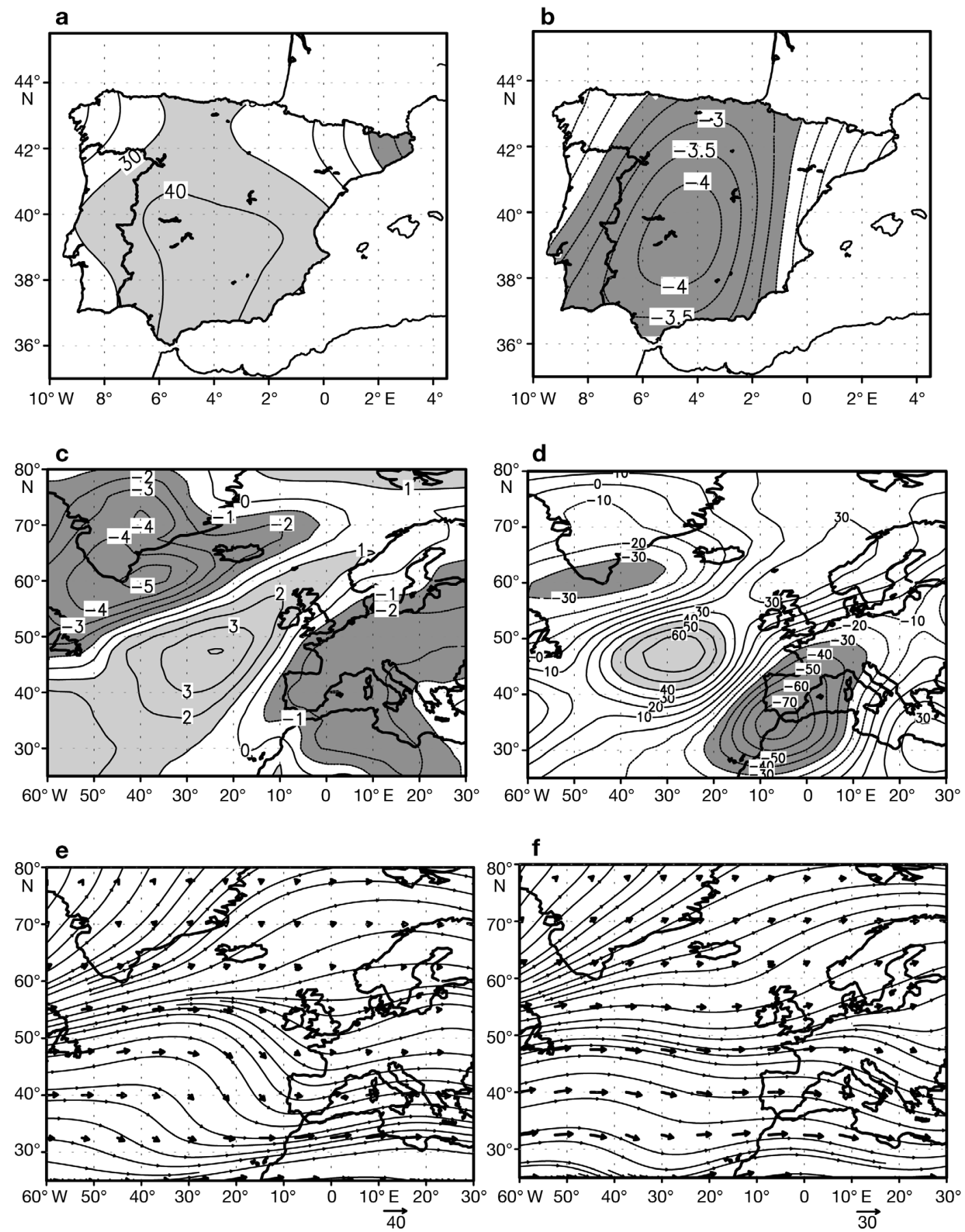

Fig. 2. Composite maps for the years with high $(1984,1988,2000,2004)$ and low $(19811992,1995,2005)$ productivity of: (a) precipitation (mm); (b) maximum temperature $\left({ }^{\circ} \mathrm{C}\right) ;(\mathrm{c})$ sea level pressure $(\mathrm{hPa}) ;$ (d) geopotential at $500 \mathrm{hPa}$. For (a-d) light $(\mathrm{dark})$ grey shading highlights positive (negative) values. Composite maps of zonal wind at $200 \mathrm{hPa}$ : (e) years with high productivity; (f) years with low productivity. The arrows beneath panels (e) and (f) indicate wind speed ( $\mathrm{m} \mathrm{s}^{-1}$ )

The relationships between $\mathrm{CP}$ and the climate fields were analysed for the months involved in the cereal cycle (October to June) by obtaining the correlation coefficients. Despite differences among months, it was found that climate in May has the strongest impact on $\mathrm{CP}$ variability, with the exception of the minimum tem- perature, which has effects on $\mathrm{CP}$ variability during December-January-February (DJF). Fig. 3a shows the correlation pattern between CP and the SPI in May. Larger correlation values were obtained toward the south of the IP. This correlation pattern resembles the spatial configuration of the second rotated EOF of SPI 
variability (Fig. 3b), which accounts for $21 \%$ of the total variance and characterizes drought variability toward the southeastern part of the IP. The time series associated with the second rotated Principal Component of SPI (RPC2_SPI_My) and the CP time series are shown in Fig. 3c. The correlation coefficient $( \pm \mathrm{SE})$ between both time series $r=0.63 \pm 0.08$ is significant at the $99 \%$ level $(\mathrm{p}=0.0001)$. Therefore, RPC2_SPI_My

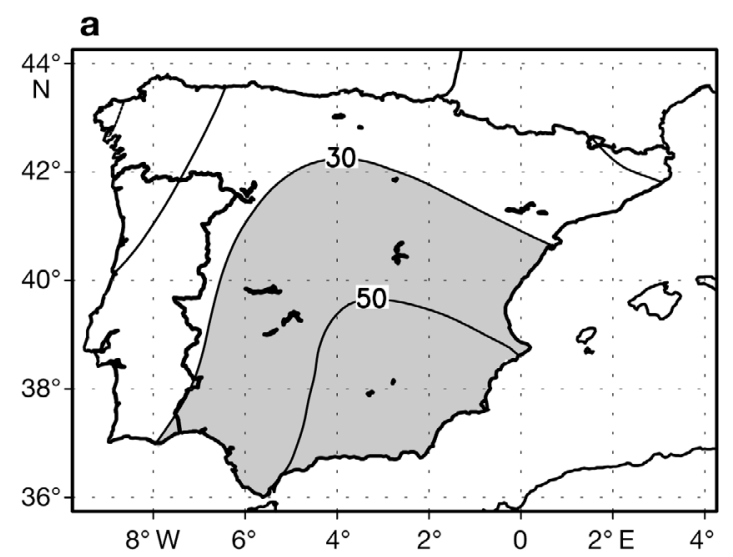

b
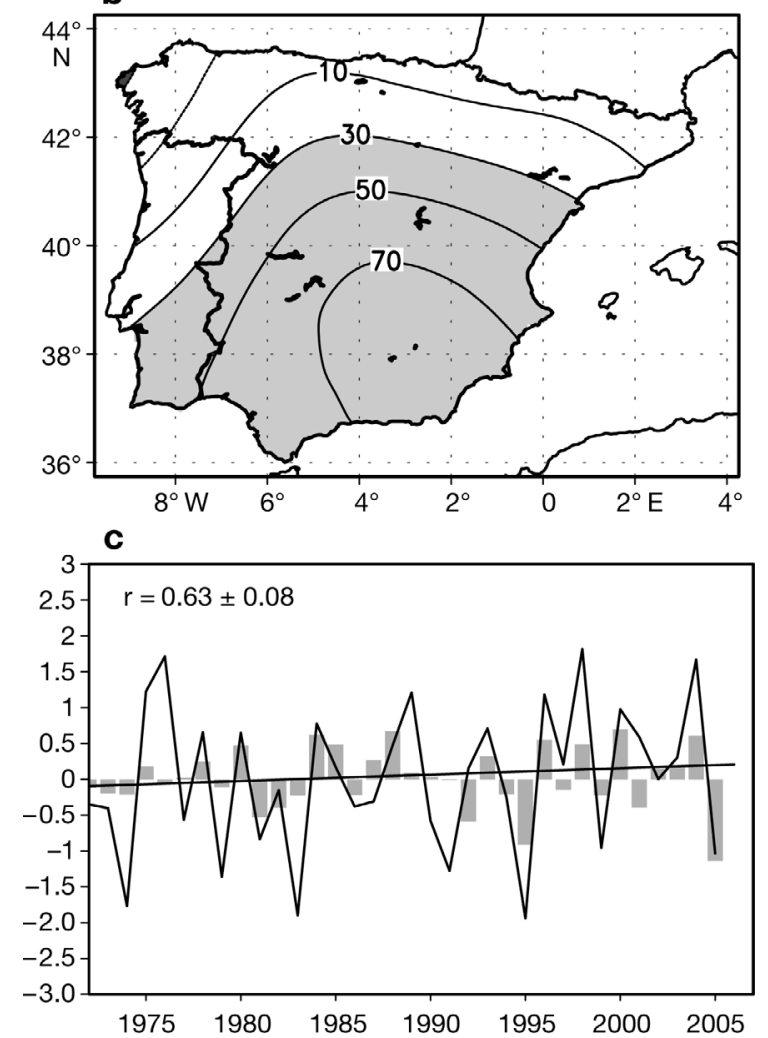

Fig. 3. (a) Correlation map between cereal productivity and standardized precipitation index (SPI; \%) for May. (b) Second rotated empirical orthogonal functions of SPI (\%) for May. The associated variance: $21 \%$. (c) Time series of cereal productivity (bars; $\mathrm{t} \mathrm{hm}^{-2}$ ) and the second principal component of SPI (RPC2_SPI_My) (line; dimensionless). For (a) and (b) light grey shading highlights positive values would be considered as a potential predictor for the regression model.

The opposite connection between CP and maximum temperature (TX) can be seen in the correlation pattern (Fig. 4a). The correlation pattern resembles the third rotated EOF of the TX. This EOF mode accounts for $24 \%$ of the total TX (Fig. $4 \mathrm{~b}$ ) and characterizes TX variability toward the southern part of the peninsula.
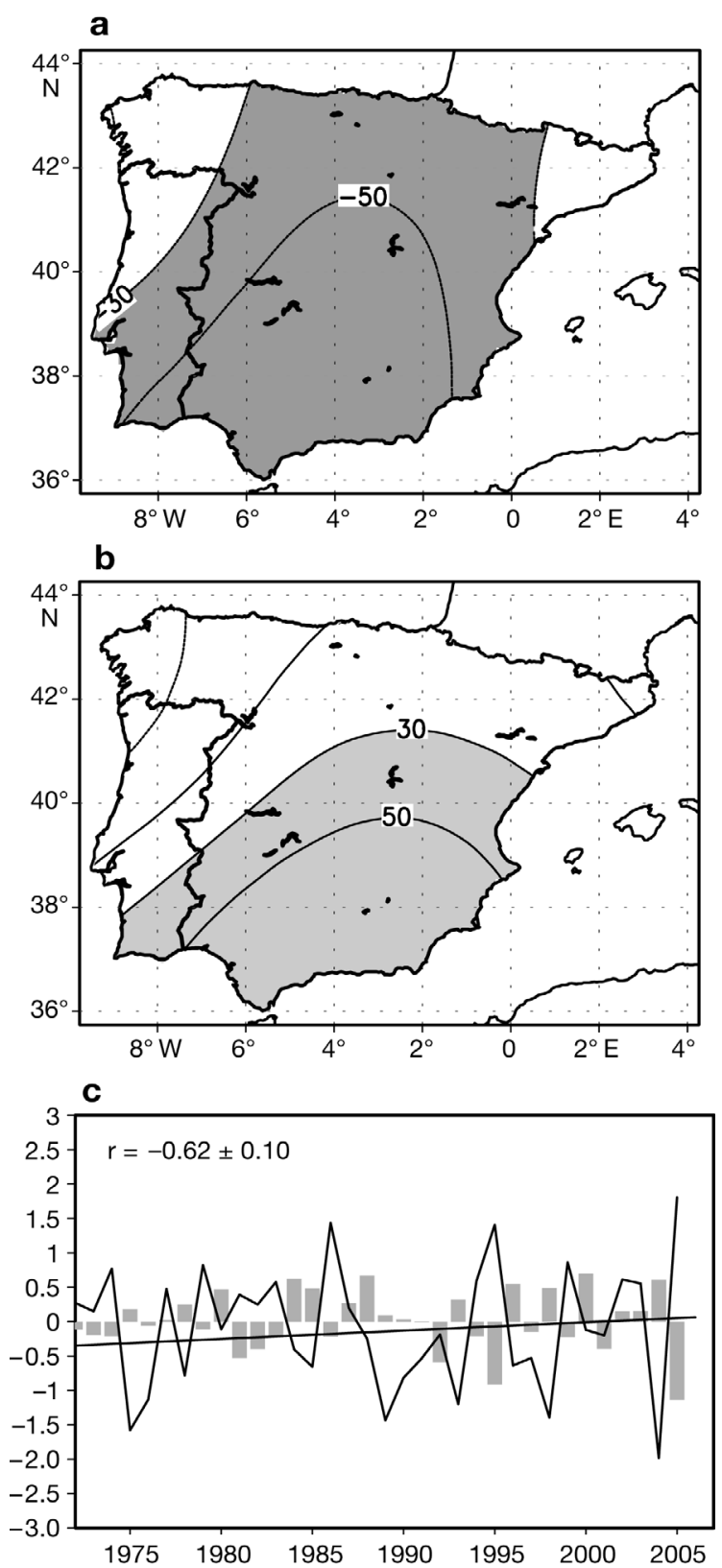

Fig. 4. (a) Correlation map between cereal productivity and monthly maximum temperature $\left(\mathrm{TX}_{i} \%\right.$ ) for May. (b) Third rotated empirical orthogonal functions of TX (\%) for May. Associated variance: $24 \%$. (c) Time series of cereal productivity (bars; $\mathrm{t} \mathrm{hm}^{-2}$ ) and the third principal component of TX (RPC3_TX_My) (line; dimensionless). For (a) and (b) light (dark) grey shading highlights positive (negative) values 
The $\mathrm{CP}$ time series and the third principal component of TX (RPC3_TX_My) are shown in Fig. 4c $(\mathrm{r}=-0.62 \pm$ $0.10 ; \mathrm{p}=0.0001)$. The RPC3_TX_My would be another potential predictor for the regression model.

The correlation pattern between $\mathrm{CP}$ and minimum temperature (TN) in winter (DJF) (Fig. 5a) resembles the first rotated EOF of TN (Fig. 5b), which accounts for $34 \%$ of total variance. The (RPC1_TN_DJF) is positively correlated with $\mathrm{CP}(\mathrm{r}=0.46 \pm 0.14 ; \mathrm{p}=0.006)$ (Fig. 5c), which would be considered as another potential predictor for the regression model.

To detect the circulation signals that affect $\mathrm{CP}$, we proceeded in a similar way to that used for the SPI and temperatures. The correlation pattern between $\mathrm{CP}$ and large-scale atmospheric fields such as SLP, JET, QU and QV was obtained and compared with the EOFs of the fields. Fig. 6a shows the correlation pattern between CP and SLP, which resembles the third rotated EOF of SLP corresponding to May (REOF3_SLP_My), describing $14 \%$ of the total variance (Fig. $6 \mathrm{~b}$ ). The corresponding principal component would be another potential predictor for the statistical model (Fig. 6c). The correlation coefficient between the RPC3_SLP_My and $\mathrm{CP}$ is $\mathrm{r}=-0.55 \pm 0.12 ; \mathrm{p}=0.0008$. The positive trend of RPC3_SLP_My gives a Kendall $z$-test value of 1.6. The increasing SLP in the western Mediterranean could impact the yield negatively. It has also been found that the $\mathrm{CP}$ is related to the Scandinavian Pattern (SCA) in spring (SCA_MAMy), the correlation coefficient being $r=0.48 \pm 0.11 ; p=0.004$. The positive phase of the SCA pattern is associated with below-average temperatures over southwestern Europe and with above-average precipitation over southern Europe, which are good atmospheric conditions for increasing $\mathrm{CP}$ in Spain. The SCA index in spring has a tendency to decrease; the Kendall $z$-test value is -1.5 (Fig. 7a), affecting the yield negatively. $\mathrm{CP}$ is also correlated with the negative phase of the North Atlantic Oscillation in May (NAO_My) $(\mathrm{r}=-0.43 \pm 0.10$, and $\mathrm{p}=0.01$ ) (Fig. 7b). This effect can be explained because in May the positive phase of the NAO causes higher TX and, in addition, the TX is correlated negatively with CP (Table 1).

Manifestations of the influence of the ENSO on the IP precipitation have been shown by Rodo et al. (1997) and Pozo-Vazquez et al. (2005). Therefore, we considered the Southern Oscillation Index (SOI) as a potential predictor because a significant correlation was found between the SOI of May and CP $(r=0.28 \pm 0.16$, $\mathrm{p}=0.03$ ) (Fig. $7 \mathrm{c}$ ). The SOI modifies the undulation of atmospheric circulation. During La Niña episodes (positive phase of the SOI) a large-scale upper-level cyclonic circulation anomaly is produced over the subtropical latitudes and these anomalies reflect the westward retraction of the jet stream (www.cpc.ncep.noaa.
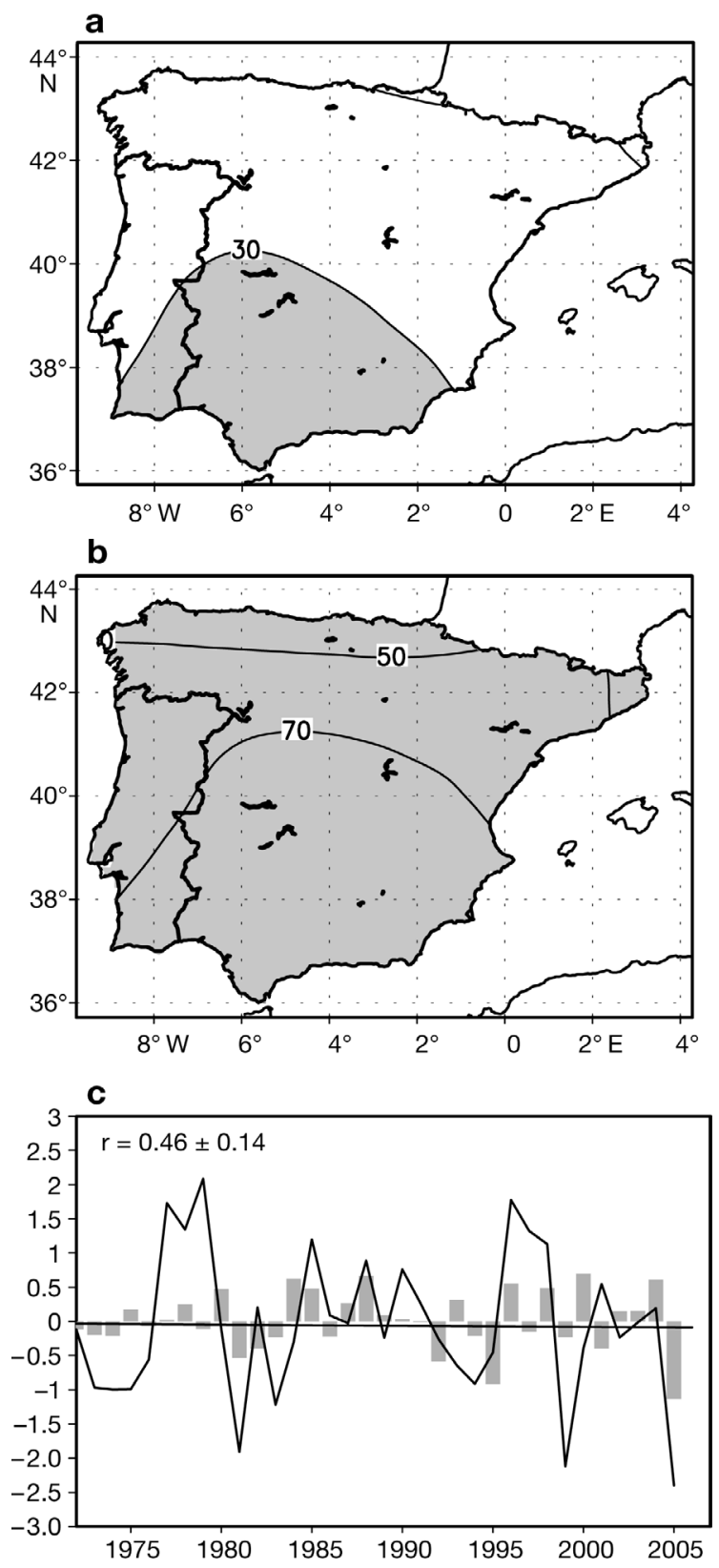

Fig. 5. (a) Correlation map between cereal productivity and monthly minimum temperature $\left(\mathrm{TN}_{i} \%\right)$ for winter. (b) First rotated empirical orthogonal functions of TN (\%) for winter. Associated variance: $34 \%$. (c) Time series of cereal productivity (bars; $\mathrm{t} \mathrm{hm}^{-2}$ ) and the first principal component of TN (RPC1_TN_DJF) (line; dimensionless). For (a) and (b) light grey shading highlights positive values

gov/products/analysis_monitoring/ensocycle/lanina_ circ.shtml). This effect could explain the relationships between the SOI and $\mathrm{CP}$, because it previously has been shown that the meridional circulation is connected with years of higher CP (Fig. 2e). Furthermore, $\mathrm{CP}$ shows a significant correlation with the zonal wind 

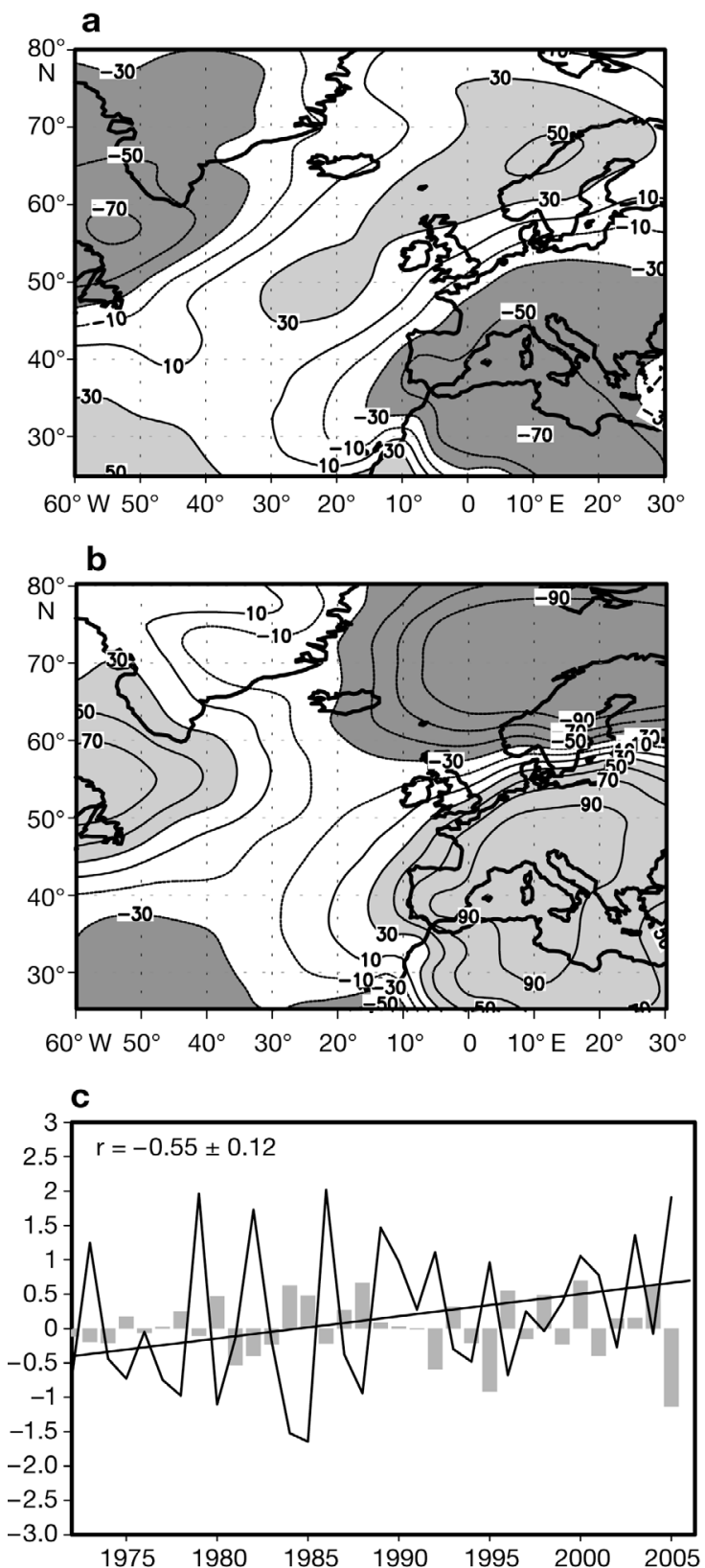

Fig. 6. (a) Correlation map between cereal productivity and monthly sea level pressure (SLP; \%) for May. (b) Third rotated empirical orthogonal functions of SLP (\%) for May. The percentage of associated variance is 14 . (c) Time series of cereal productivity (bars; $\mathrm{t} \mathrm{hm}^{-2}$ ) and the third principal component of SLP (RPC3_SLP_My) (line; dimensionless). For (a) and (b) light (dark) grey shading highlights positive (negative) values

at $200 \mathrm{hPa}$ level (JET) in May (Fig. 8a) and the correlation pattern resembles the first EOF of the JET (Fig. $8 b)$, which accounts for $29 \%$ of the total variance. The correlation coefficient between CP and the PC1_JET is $r=0.63 \pm 0.11(p=0.0001)$ (Fig. 8c). Moisture fluxes are also linked to CP. Table 1 summarizes the significant
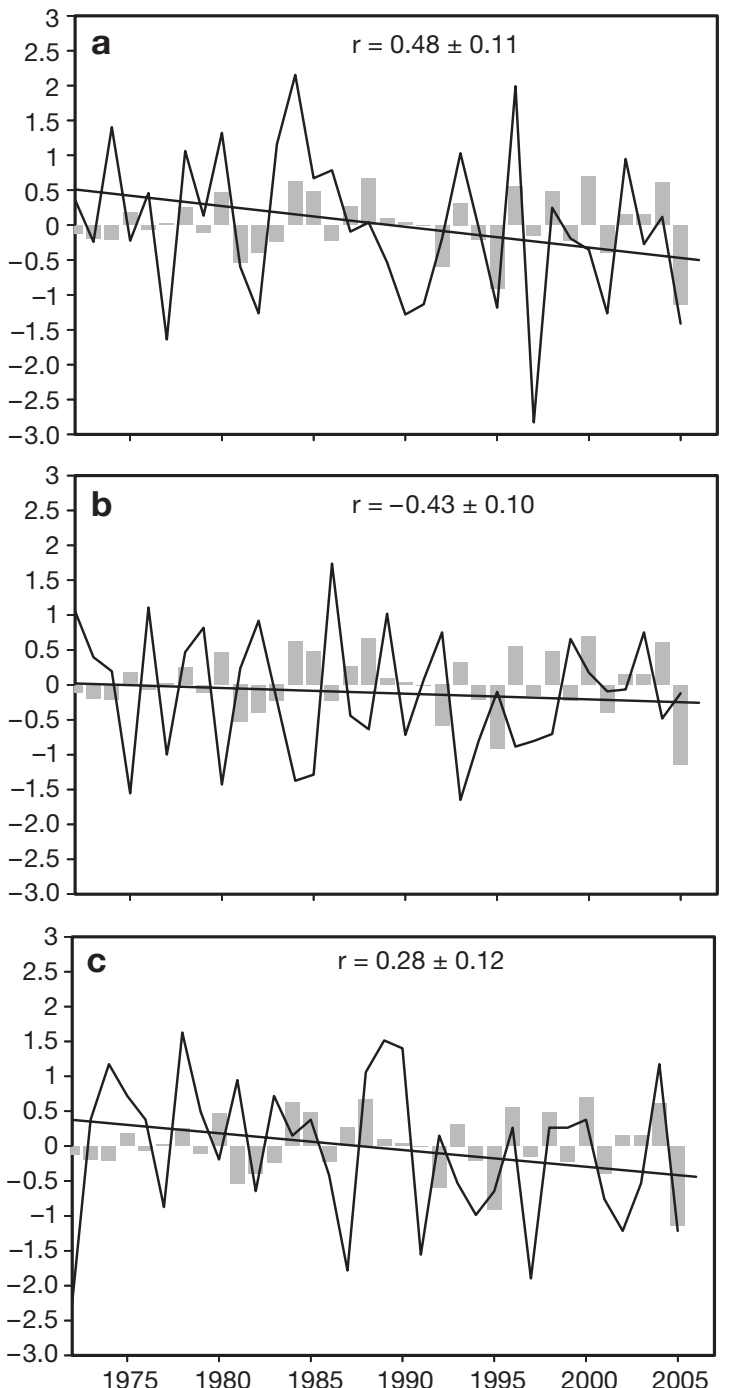

Fig. 7. Time series of cereal productivity (bars; $\mathrm{t} \mathrm{hm}^{-2}$ ) and: (a) the Scandinavian Pattern of Spring (SCA_MAMy); (b) the North Atlantic Oscillation of May (NAO_My); (c) the Southern Oscillation Index of May (SOI_My) (lines; dimensionless)

correlation coefficients between $\mathrm{CP}$ and some potential predictors and between the predictors themselves; only values with a confidence level higher than $95 \%$ were included.

\subsection{Modelling approach}

Based on the previous results, a statistical model was proposed to estimate the response of winter CP to climate factors. The statistical model included the Standardized Precipitation Index (RPC2_SPI_My), the minimum temperature (RPC1_TN_DJF), the Scandinavian Pattern (SCA_MAMy), the Southern Oscillation index (SOI_My), the zonal wind at 200 hPa (PC1_JET_My) 
Table 1. Significant correlation coefficients (r) between potential predictors and cereal productivity (CP). For explanation of potential predictor keys see 'Results'

\begin{tabular}{|lrcccccc|}
\hline & CP & $\begin{array}{c}\text { RPC2_- } \\
\text { SPI_My }\end{array}$ & $\begin{array}{c}\text { RPC3_ } \\
\text { TX_My }\end{array}$ & $\begin{array}{r}\text { RPC3_ } \\
\text { SLP_My }\end{array}$ & $\begin{array}{r}\text { PC1_- JET_My } \\
\text { PC2_-My }\end{array}$ & $\begin{array}{c}\text { RPC3 } \\
\text { QV_My }\end{array}$ \\
\hline RPC2_SPI_My & 0.63 & 1 & & & & & \\
RPC3_TX_My & -0.62 & -0.77 & 1 & & & & \\
RPC1_TN_DJF & 0.46 & & & & & & \\
RPC3_SLP_My & -0.54 & & 0.37 & 1 & & & \\
PC1_JET_My & 0.63 & 0.51 & -0.76 & -0.55 & 1 & & \\
PC2_QU_My & -0.49 & -0.40 & 0.52 & 0.49 & -0.47 & 1 & 1 \\
RPC3_QV_My & -0.50 & & & 0.67 & -0.67 & 0.45 & 1 \\
NAO & -0.44 & & 0.36 & 0.64 & & 0.44 & 0.48 \\
SCA & 0.49 & & & -0.48 & & & \\
SOI_My & 0.28 & & -0.38 & & & & \\
\hline
\end{tabular}

and the North Atlantic Oscillation (NAO_My). Maximum temperature was not entered into the model because its effect was represented by other variables such as the SPI and JET. Neither were moisture fluxes and the sea level pressure (RPC3_SLP) entered into the model because they are associated with the NAO index and JET variable. The results of the model give a correlation coefficient with the observed CP data of $r=0.86 \pm 0.05$ for the entire period. This means that approximately $75 \%$

Table 2. Correlation coefficient $(\mathrm{r} \pm \mathrm{SE})$ between cereal productivity $(\mathrm{CP})$ and the climate variables entered into the statistical model. Parameters of the model equation: mean (CM), lower (CL) and upper (CU). For explanation of the climate predictor keys see 'Results'

\begin{tabular}{|lcccccc|}
\hline & RPC2_SPI_My & RPC1_TN_DJF & PC1_JET_My & NAO_My & SCA_MAMy & SOI_A \\
\hline r & $0.63 \pm 0.08$ & $0.46 \pm 0.14$ & $0.63 \pm 0.11$ & $-0.43 \pm 0.10$ & $0.48 \pm 0.11$ & $0.28 \pm 0.12$ \\
CM & 0.1346 & 0.1219 & 0.0998 & -0.1026 & 0.125 & 0.022 \\
CL & 0.0324 & 0.037 & -0.0079 & -0.21 & 0.036 & -0.0708 \\
CU & 0.2368 & 0.2068 & 0.2075 & 0.0043 & 0.2137 & 0.1148 \\
\hline
\end{tabular}
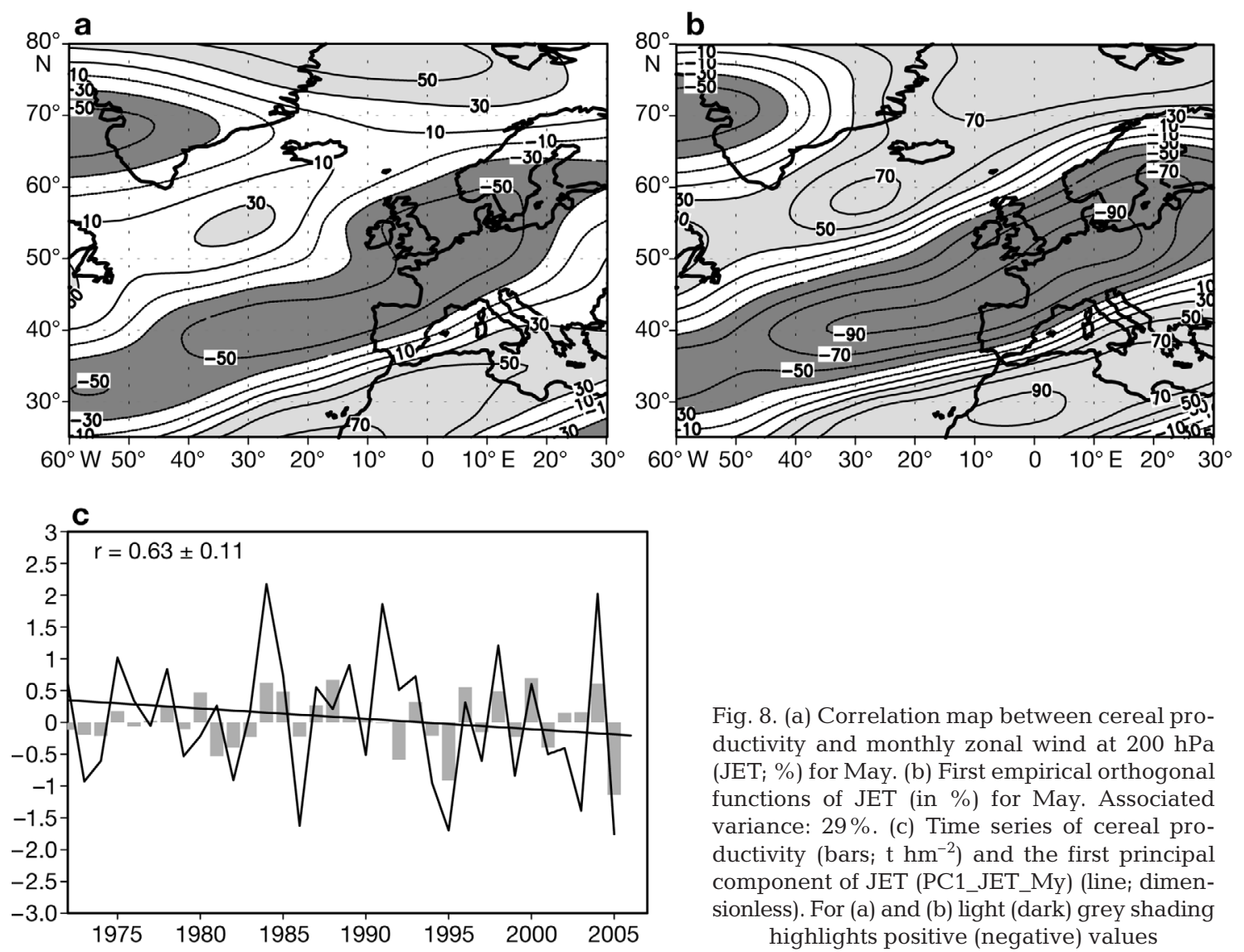

Fig. 8. (a) Correlation map between cereal productivity and monthly zonal wind at $200 \mathrm{hPa}$ (JET; \%) for May. (b) First empirical orthogonal functions of JET (in \%) for May. Associated variance: $29 \%$. (c) Time series of cereal productivity (bars; $\mathrm{t} \mathrm{hm}^{-2}$ ) and the first principal component of JET (PC1_JET_My) (line; dimensionless). For (a) and (b) light (dark) grey shading highlights positive (negative) values 


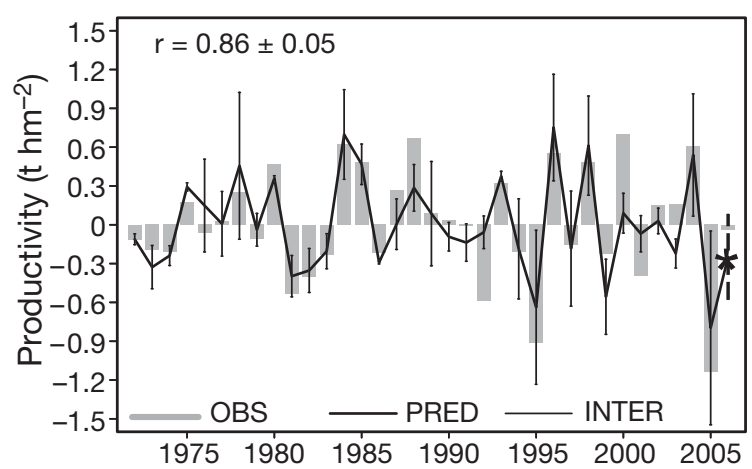

Fig. 9. Time series of cereal productivity observed (OBS; grey bars), the results of the regression model (PRED; thick line); and the confidence interval for the estimations (INTER; error bars). The vertical dashed line and the asterisk represent the predicted values for the year 2006

of the year-to-year CP variance is described by the climate predictors. Fig. 9 shows the model estimations, with confidence intervals (error bars), evaluated by cross-validation. Table 2 depicts the results of the correlation coefficients (r) between each predictor and $\mathrm{CP}$, including also the mean (CM), lower (CL) and upper (CU) model regression coefficients.

The model considers the benefit effects of abundant precipitation (SPI) and dynamic aspects of the air mass represented by the JET, NAO and SCA indices during the maturation stage of CP. Furthermore, it contains the favourable effects of warm winters at the beginning of the cereal growing season (DJF). The model is suitable for certain applications; for example, to provide a description of the meteorological aspects responsible for $\mathrm{CP}$ variations. However, there is a limitation to the application of this approach for forecasting purposes since the regression coefficients were fitted for this particular dataset and the stationarity of the relationships must be assessed by analysing longer time series. The model has been applied to obtain the winter cereal yield for the year 2006 and compared the result with the yield observed. The statistical approach gives predicted values between 2.09 and $2.74 \mathrm{t} \mathrm{hm}^{-2}$, while the observed value was 2.63. There is a good correspondence between predicted and observed values. However, we should not consider this result representative of the good performance of the model because the values are close to the mean for the year 2006, which is the most probable data.

\section{CONCLUSIONS}

In this study we derived a model to capture the effects of climate variables on $\mathrm{CP}$ in Spain to obtain their impact on this yield. The model considers the beneficial effects of abundant precipitation (SPI) and the dynamic aspects of the air mass represented by the JET, NAO and SCA indices, during the maturation stage of cereal. In addition it takes into account the favourable effects of warm winters at the beginning of the cereal growing season. The influence of the SOI on winter cereal yield could be explained by its indirect effects on the undulation of atmospheric circulation. The prevalent meridional circulation seems to be connected with years of higher cereal yield, as mentioned above. The trend observed in some of the large-scale variables - for example, the increase in SLP towards the western Mediterranean and the decrease in the SCA index - could affect the yield negatively.

Our study provides a description of the relationships between the climatic factors and $\mathrm{CP}$ variations that could be used to translate climate information into production for farming decisions. The model was applied to estimate CP for the year 2006, with a very good correspondence between the predicted and observed values. The potential usefulness of this study for future research is to apply the probabilistic seasonal forecast of climate variables to the cereal production for crop management decisions; to learn about the agricultural impact of climate change by taking into account simulated large scale variables of the GCM output; and to downscale suitable standardized input variables for use with crop model simulations. The methodology used in this study could be applied to any region although the climate influence may provide different results.

Acknowledgements. The authors thank the 2 anonymous reviewers for their comments and suggestions, the Meteorology Institutes of Spain and Portugal for in situ data; NCEP/NCAR for reanalysis data, the GrADS software developers and the SCI of the University of Salamanca for the English revision. This work was funded by National Research Project MEC-CGL2005-06600CO3-01/CLI and the Regional Project of Castilla and León SA039/A05 with FEDER European funds.

\section{LITERATURE CITED}

Adejuwon JO (2006) Food crop production in Nigeria. II. Potential effects of climate change. Clim Res 32:229-245 Alexander LV, Zhang X, Peterson TC, Caesar J and 20 others (2006) Global observed changes in daily climate extremes of temperature and precipitation. J Geophys Res D 111:22

Alexandrov VA, Hoogenboom G (2000) The impact of climate variability and change on crop yield in Bulgaria. Agric For Meteorol 104:315-327

Alexandrov VA, Hoogenboom G (2001) Climate variation and crop production in Georgia, USA, during the twentieth century. Clim Res 17:33-43

Cantelaube P, Terres JM (2005) Seasonal weather forecasts for crop yield modeling in Europe. Tellus Ser A Dyn Meteorol Oceanogr 57:476-487 
Corte-Real J, Qian BD, Xu H (1998) Regional climate change in Portugal: precipitation variability associated with large-scale atmospheric circulation. Int $\mathrm{J}$ Climatol 18: 619-635

Frich P, Alexander LV, Della-Marta P, Gleason B, Haylock M, Tank A, Peterson T (2002) Observed coherent changes in climatic extremes during the second half of the twentieth century. Clim Res 19:193-212

Hansen JW, Sivakumar MVK (2006) Advances in applying climate prediction to agriculture. Clim Res 33:1-2

Hansen JW, Challinor A, Ines A, Wheeler T, Moron V (2006) Translating climate forecasts into agricultural terms: advances and challenges. Clim Res 33:27-41

Harrison PA, Porter JR, Downing TE (2000) Scaling-up the AFRCWHEAT2 model to assess phenological development for wheat in Europe. Agric For Meteorol 101:167-186

Hayes MJ, Svoboda MD, Wilhite DA, Vanyarkho OV (1999) Monitoring the 1996 drought using the standardized precipitation index. Bull Am Meteorol Soc 80:429-438

Iglesias A, Quiroga S (2007) Measuring the risk of climate variability to cereal production at five sites in Spain. Clim Res 34:47-57

Jolliffe I (2002) Principal component analysis. Springer, New York

Jones GV, Davis RE (2000) Using a synoptic climatological approach to understand climate-viticulture relationships. Int J Climatol 20:813-837

Kalnay E, Kanamitsu M, Kistler R, Collins W and 18 others (1996) The NCEP/NCAR 40-year reanalysis project. Bull Am Meteorol Soc 77:437-471

Landau S, Mitchell RAC, Barnett V, Colls JJ, Craigon J, Payne RW (2000) A parsimonious, multiple-regression model of wheat yield response to environment. Agric For Meteorol 101:151-166

Lobell DB, Field CB (2007) Global scale climate-crop yield relationships and the impacts of recent warming. Environ Res Lett 2, doi:10.1088/1748-9326/2/1/014002

Mearns LO, Giorgi F, McDaniel L, Shields C (2003) Climate scenarios for the southeastern US based on GCM and regional model simulations. Clim Change 60:7-35

Moreno JM (2005) A preliminary general assessment of the impacts in Spain due to the effects of climate change. Ministerio del Medio Ambiente, Madrid

Nicholls N (1997) Increased Australian wheat yield due to recent climate trends. Nature 387:484-485

Penalba OC, Bettolli ML, Vargas WM (2007) The impact of climate variability on soybean yields in Argentina. Multivariate regression. Meteorol Appl 14:3-14

Phillips JG, Cane MA, Rosenzweig C (1998) ENSO, seasonal rainfall patterns and simulated maize yield variability in Zimbabwe. Agric For Meteorol 90:39-50

Podesta GP, Messina CD, Grondona MO, Magrin GO (1999) Associations between grain crop yields in central-eastern

Editorial responsibility: Nils Chr. Stenseth,

Oslo, Norway
Argentina and El Niño-Southern Oscillation. J Appl Meteorol 38:1488-1498

Pozo-Vazquez D, Gamiz-Fortis SR, Tovar-Pescador J, Esteban-Parra MJ, Castro-Diez Y (2005) El Nino Southern oscillation events and associated European winter precipitation anomalies. Int J Climatol 25:17-31

Press WH, Teukolsky SA, Vetterling WT, Flanery BP (1996) Numerical recipes in Fortran 77: the art of scientific computing. Cambridge University Press, Cambridge

Rodo X, Baert E, Comin FA (1997) Variations in seasonal rainfall in southern Europe during the present century: relationships with the North Atlantic Oscillation and the El Nino Southern Oscillation. Clim Dyn 13:275-284

Rodriguez-Puebla C, Brunet M (2007) Variability and climate change. In: Cuadrat-Prats JM, Martin-Vide J (eds) Spanish climatology: past, present and future. Prensas Universitarias de Zaragoza, Zaragoza, p 331-390

Rosenzweig C, Tubiello FN, Goldberg R, Mills E, Bloomfield J (2002) Increased crop damage in the US from excess precipitation under climate change. Global Environ Change Hum Policy Dimensi 12:197-202

Schroter D, Cramer W, Leemans R, Prentice IC and 31 others (2005) Ecosystem service supply and vulnerability to global change in Europe. Science 310:1333-1337

Sivakumar MVK (2006) Climate prediction and agriculture: current status and future challenges. Clim Res 33:3-17

Song YL, Chen DL, Dong WJ (2006) Influence of climate on winter wheat productivity in different climate regions of China, 1961-2000. Clim Res 32:219-227

Stenseth NC, Mysterud A, Ottersen G, Hurrell JW, Chan KS, Lima M (2002) Ecological effects of climate fluctuations. Science 297:1292-1296

Tao FL, Yokozawa M, Zhang Z, Hayashi Y, Grassl H, Fu CB (2004) Variability in climatology and agricultural production in China in association with the East Asian summer monsoon and El Nino Southern Oscillation. Clim Res 28: $23-30$

Thomson AM, Rosenberg NJ, Izaurralde RC, Brown RA (2005) Climate change impacts for the conterminous USA: an integrated assessment. Part 2: Models and validation. Clim Change 69:27-41

Vicente-Serrano SM (2006) Spatial and temporal analysis of droughts in the Iberian Peninsula (1910-2000). Hydrol Sci J 51:83-97

Vicente-Serrano SM, Cuadrat-Prats JM, Romo A (2006) Early prediction of crop production using drought indices at different time-scales and remote sensing data: application in the Ebro valley (North-East Spain). Int J Remote Sens 27:511-518

von Storch H, Zwiers F (1999) Statistical analysis in climate research. Cambridge University Press, Cambridge

Wilks DS (2006) Statistical methods in the atmospheric sciences. Academic Press, Amsterdam

Submitted: December 15, 2006; Accepted: January 16, 2007 Proofs received from author(s): July 17, 2007 